\title{
Diurnal variation in phagocytic activity of splenic phagocytes in freshwater teleost Channa punctatus: melatonin and its signaling mechanism
}

\author{
Brototi Roy, Rajeev Singh, Sunil Kumar and Umesh Rai \\ Department of Zoology, University of Delhi, Delhi-110 007, India \\ (Correspondence should be addressed to U Rai; Email: rai_u@rediffmail.com)
}

\begin{abstract}
The aim of the present study was to understand the rhythmic changes in innate immune response in freshwater fish Channa punctatus. Furthermore, the putative role of melatonin as the zeitgeber was explored. The phagocytic activity of splenic phagocytes assessed at 6-h intervals showed higher phagocytic activity during light phase than dark phase. The increased phagocytic activity during light phase was diminished by melatonin administration at 09:00 h. Implication of melatonin in control of diurnal variation in phagocytic activity was substantiated by administering irreversible tryptophan hydroxylase inhibitor, para-chlorophenylalanine $(\mathrm{pCPA})$ at 18:00 h. pCPA abrogated the decrease of phagocytosis observed during dark phase, and the same was restored after melatonin administration. The direct involvement of melatonin in modulation of phagocytosis was demonstrated following in vitro experiments. Melatonin suppressed the phagocytic activity in a concentration-dependent manner without affecting the
\end{abstract}

viability of phagocytes. The existence of functional membrane-bound melatonin receptors on fish phagocytes was pharmacologically demonstrated. Luzindole, melatonin membrane receptor antagonist, completely blocked the inhibitory effect of melatonin on phagocytosis. Further receptor-coupled adenylate cyclase-protein kinase A (PKA) pathway was implicated in transducing the melatonin effect as both adenylate cyclase and PKA inhibitor completely nullified the melatonininduced suppression. An increased intracellular cAMP level in response to melatonin ascertained the second messenger status of cAMP for downstream signaling. However, manipulation of phospholipase $\mathrm{C} / \mathrm{PKC}$ failed to influence the effect of melatonin on phagocytic activity. These observations in C. punctatus evidenced the diurnal rhythmicity in phagocytic activity that is regulated by melatonin following membrane-bound receptorcoupled cAMP-PKA pathway.

Journal of Endocrinology (2008) 199, 471-480

\section{Introduction}

Phagocytes are the important constituent of the innate immune system and critical for the survival of organisms, especially fishes in which innate immune responses undergo compensatory hypertrophy when the specific immune responses are suppressed (Manning \& Nakanishi 1996). One of the most fundamental defense mechanisms through which phagocytes destroy pathogens is phagocytosis (Neumann et al. 2001). Interestingly, the phagocytes in mammals and birds are reported to exhibit day-night variation in their phagocytic activity (Barriga et al. 2001, Berger \& Slapničková 2003, Hriscu 2004). With regard to ectothermic vertebrates, a single report is available and confined to fishes, seabream and sea bass in which the diurnal variation is shown in the humoral immune responses (Esteban et al. 2006). However, the diurnal rhythmicity in phagocytic activity has not been explored to date in ectotherms.

The pineal hormone, melatonin, is implicated in the regulation of diurnal variation in phagocytic activity of leucocytes based on correlation between circadian pattern of plasma melatonin and phagocytosis in birds (Rodríguez et al. 1999) and mammals (Barriga et al. 2001). It is of interest to note that melatonin biosynthesis has also been described in human peripheral blood mononuclear leukocytes (Finocchiaro et al. 1988, 1991), mouse and human bone marrow cells (Conti et al. 2000), and human lymphocytes (Carrillo-Vico et al. 2004). However, the physiological significance of immune cellsderived melatonin is far from clear.

The immunomodulatory role of melatonin in endothermic vertebrates has been extensively studied (review: Guerrero \& Reiter 2002). In ectothermic vertebrates, there is a single study that demonstrates the direct role of melatonin in control of phagocyte functions in fishes (Cuesta et al. 2007). However, the involvement of melatonin in regulation of diurnal variation in immune responses is not explored despite that the serum melatonin level displays a diurnal rhythmicity in all the ectothermic vertebrates including fishes (Falcón et al. 2007). The present study, for the first time in ectothermic vertebrates, was aimed to demonstrate the diurnal variation in phagocytic activity and its control by melatonin. Furthermore, the 
receptor-coupled downstream signaling cascade of melatonin in fish splenic phagocyte was explored. The investigation was carried out in the freshwater teleost Channa punctatus, commonly known as spotted murrel. They can survive in swamps and derelict water bodies by virtue of accessory respiratory organ, and therefore, is the mainstay of pond fishery in the Indian subcontinent. Their easy availability, small size and nutritive value makes it an excellent experimental model.

\section{Materials and Methods}

\section{Animals}

Adult female fish (C. punctatus) weighing 80-100 g were procured from the neighboring state of Delhi, India (latitude $28 \cdot 38^{\prime} \mathrm{N}$, longitude $77 \cdot 2^{\prime} \mathrm{E}$ ) and acclimated to the laboratory conditions for a month at $25^{\circ} \mathrm{C} \pm 2{ }^{\circ} \mathrm{C}$. The light regimen was adjusted from 07:00 to 19:00 h (12h light:12h darkness). They were able to fed ad libitum with minced beef liver.

The guidelines of the 'Committee for the Purpose of Control and Supervision of Experiments on Animals', Ministry of Statistics and Programme Implementation, Government of India were followed in designing the experiments as well as maintenance and killing of fish.

\section{Reagents and culture medium}

Tissue culture medium RPMI-1640 (Sigma Chemicals) was supplemented with $40 \mu \mathrm{g} / \mathrm{ml}$ of antibiotic gentamicin, $100 \mu \mathrm{g} / \mathrm{ml}$ streptomycin, $100 \mathrm{IU} / \mathrm{ml}$ penicillin, $5.94 \mathrm{mg} / \mathrm{ml}$ HEPES buffer (Sisco Research Laboratories, Pvt Ltd., Mumbai, India), and 2\% heat-inactivated FCS (FCS; Biological Industries, Beth Haemek, Israel) and is referred to as the complete culture medium.

Melatonin, para-chlorophenylalanine (pCPA), luzindole, SQ 22536, H-89, U-73122, staurosporine, 3-isobutyl-1methyl-xanthine (IBMX), and cAMP enzyme immunoassay kit were purchased from Sigma Chemicals. Two-phenoxyethanol, methanol, dimethyl sulfoxide (DMSO) and Giemsa stain were purchased from Sisco Research Laboratories (SRL) Pvt. Ltd/Merck Ltd. Stock solution $\left(10^{-3} \mathrm{~mol} / \mathrm{l}\right)$ of melatonin and luzindole was made in PBS $(1 \times, \mathrm{pH} 7 \cdot 8)$ containing 3\% ethanol. Further dilutions were made in PBS. pCPA was dissolved in alkaline PBS (containing $0 \cdot 2 \%$ $\mathrm{NaOH}$ ). The respective diluent was added to the vehicle/ culture medium used for their respective controls.

\section{Preparation of splenic phagocyte monolayer}

Phagocytes were isolated following the protocol of Roy \& Rai (2008). Briefly, fish were sacrificed by a lethal dose of 2-phenoxyethanol (1:1000 v/v), spleen were dissected out, and forced through a nylon mesh of pore size $90 \mu \mathrm{m}$ into chilled PBS $(1 \times, \mathrm{pH} 7 \cdot 8)$. The cell suspension was centrifuged at $600 \boldsymbol{g}$ for $15 \mathrm{~min}$. The supernatant was discarded. Red blood corpuscles (RBCs) were removed by water shock treatment. After washing with PBS, the splenic cell pellet was resuspended in complete culture medium. Two hundred microliter of cell suspension $\left(1 \times 10^{6}\right.$ cells $\left./ \mathrm{ml}\right)$ was flooded on each pre-washed microscopic slide. Phagocytes were allowed to adhere for $2 \mathrm{~h}$. The non-adherent cells were washed off with PBS.

The phagocyte monolayer was prepared by pooling the spleen of fish to minimize the individual variation. Four fish per experimental group were killed and three slides were made from the pool of splenic cell suspension. All the experiments were performed at $25{ }^{\circ} \mathrm{C}( \pm 0 \cdot 1)$ with $5 \% \mathrm{CO}_{2}$.

\section{Preparation of yeast cell suspension}

Heat-killed yeast cell suspension was made by warming commercial Baker's yeast ( $3 \mathrm{mg} / \mathrm{ml} \mathrm{PBS,} \mathrm{pH} 7 \cdot 8$ ) at $80{ }^{\circ} \mathrm{C}$ for $15 \mathrm{~min}$. The pellet was washed and resuspended in the complete culture medium.

\section{Phagocytic assay}

For phagocytic assay, the phagocyte monolayer was incubated with heat-killed yeast cells for $60 \mathrm{~min}$, washed with PBS, fixed in methanol, and stained with Giemsa. Without any predetermined sequence or scheme, $\sim 200$ phagocytes/slide were observed. Phagocytes that engulfed one or more than one yeast cell were considered positive cells. The percentage phagocytosis and the phagocytic index were calculated following the formulae: percentage phagocytosis - number of positive cells per 100 phagocytes observed; phagocytic index - average number of engulfed yeast cells per positive phagocyte $X$ percentage phagocytosis.

\section{Experiments}

Diurnal variation in phagocytic activity Fish were killed at 6-h time intervals, i.e. 12:00, 18:00, 24:00, and 06:00 h. At each time, the spleens of four fish were pooled to prepare the phagocyte monolayer in triplicate for phagocytic assay.

\section{Role of pineal hormone melatonin in diurnal variation in phagocytic activity}

Effect of tryptophan hydroxylase inhibitor ( $p C P A)$. pCPA is a known irreversible tryptophan hydroxylase inhibitor, and hence, diminishes the melatonin synthesis (Carrillo-Vico et al. 2005). A single dose of pCPA (100 mg/ $\mathrm{kg}$ body weight) in C. punctatus is reported to considerably reduce serotonin that is the precursor of melatonin, within $2 \mathrm{~h}$ of its administration. The serotonin level in pCPA-treated fish remains subdued for the next 72 h (Joy \& Khan 1991). Therefore, the same dose of pCPA was used in the present study. The comparable volume of vehicle $(0 \cdot 25 \mathrm{ml}$ PBS containing $0 \cdot 2 \% \mathrm{NaOH} /$ fish $)$ was injected in fish that were used as control. The injections were given i.p. before the onset of dark phase (18:00 h) and the fish (4 fish/group) were killed at 24:00 h. A separate control 
group of normal fish that were not subjected to any injection was made to compare the effect of vehicle injection. Spleens were dissected out and processed for phagocytosis.

Another experiment was also performed in which fish were subjected to a prolonged pCPA treatment. The first injection of pCPA (100 mg/kg body weight) was administered at 18:00 h. After $72 \mathrm{~h}$, the second injection of pCPA at the same dose was given and fish were killed at 24:00 h. The respective volume of vehicle was administered to fish kept as control.

Melatonin replacement therapy. The dose of melatonin was selected based on literature available in spotted murrel $C$. punctatus (Joy \& Khan 1991) and also our pilot experiment. A single dose of melatonin $(1.5 \mathrm{mg} / \mathrm{kg}$ body weight, i.p.) was administered at 21:00 h to four pCPA-treated fish (single dose of $100 \mathrm{mg} \mathrm{pCPA} / \mathrm{kg}$ body weight at 18:00 h). Equal number of pCPA-treated fish received the comparable volume of vehicle $(0.25 \mathrm{ml} /$ fish $)$ and considered as control. Fish were killed at 24:00, their spleen were dissected out, and processed for phagocytic assay. The experimental manipulations during dark phase were carried out under dim red light.

Melatonin administration during light phase. In this experiment, fish were administered melatonin during light phase. Six groups, each of four fish, were made. Fish of first, second, third and fourth groups were given a single injection (i.p.) of different doses of melatonin ranging from $0 \cdot 25,0 \cdot 5,1 \cdot 5$, and $3.0 \mathrm{mg} / \mathrm{kg}$ body weight respectively. The injection was administered at 09:00 h. As control, fish of the fifth group were injected with comparable volume of vehicle $(0.25 \mathrm{ml} /$ fish $)$. In the sixth group, fish were not subjected to any injection. Fish were killed after $3 \mathrm{~h}$ of injection. The splenic phagocyte monolayer from each group was processed for phagocytic assay.

\section{In vitro experiments}

For each in vitro experiment performed during light phase, spleen of four fish were pooled to prepare the phagocyte monolayer. Each experiment was repeated thrice with different fish to verify the reproducibility of the results.

Time-dependent effect of melatonin Splenic phagocytes were incubated with $10^{-8} \mathrm{~mol} / \mathrm{l}$ melatonin for different time intervals 30, 60, and $90 \mathrm{~min}$. After treatment, the monolayer was washed and processed for phagocytosis. Phagocytes incubated in medium alone for $90 \mathrm{~min}$ were considered as control. The concentration of melatonin for time-dependent experiment was determined based on literature available on in vitro effect of melatonin on fish leukocytes and pituitary cells (Falcón et al. 2003, Cuesta et al. 2007).

Concentration-dependent effect of melatonin The physiological concentration of plasma melatonin in teleost ranges from $400 \mathrm{pg} / \mathrm{ml}^{-1} \mathrm{ng} / \mathrm{ml}$ (Kezuka et al. 1988, Zachmann et al. 1992, Randall et al. 1995). Therefore, phagocytes were incubated with varying concentrations of melatonin i.e. $10^{-12}, 10^{-11}, 10^{-10}, 10^{-9}$, and $10^{-8} \mathrm{~mol} / 1$ for $1 \mathrm{~h}$. Cells incubated in medium alone for the respective time period were used as control. The incubation time was determined based on the time-dependent experiment. After treatment, cells were washed and processed for phagocytic assay.

Effect of melatonin receptor blocker (luzindole) The pilot experiments were performed with melatonin receptor blocker, luzindole, to determine the effective incubation time and concentration at which it could block the melatonin action and had no effect of its own.

The phagocyte monolayer was pretreated with $10^{-6} \mathrm{~mol} / 1$ of luzindole for $30 \mathrm{~min}$ and then exposed to $10^{-8} \mathrm{~mol} / 1$ melatonin for $1 \mathrm{~h}$. As controls, the following groups were made: i) cells incubated in medium alone for a total duration of $90 \mathrm{~min}$, ii) phagocytes incubated with $10^{-6} \mathrm{~mol} / 1$ luzindole for $30 \mathrm{~min}$ and then incubated in medium alone for $1 \mathrm{~h}$, iii) phagocytes incubated in medium alone for $30 \mathrm{~min}$ and then exposed to $10^{-8} \mathrm{~mol} / 1$ melatonin for $1 \mathrm{~h}$. After treatment, the monolayer was processed for phagocytic assay.

Downstream signaling cascade for melatonin To explore the involvement of phospholipase C (PLC)-coupled protein kinase $\mathrm{C}(\mathrm{PKC})$ signaling pathway or adenylate cyclase-coupled protein kinase A (PKA) pathway in mediating melatonin effect on phagocytosis, effect of PLC inhibitor, PKC inhibitor, adenylate cyclase inhibitor, and PKA inhibitor on melatonin-induced inhibition of phagocytosis was studied. Also, intracellular cAMP level was assayed to ascertain the PKA involvement.

\section{Effect of PLC inhibitor (U73122) and PKC inhibitor (staurosporine)}

Phagocyte monolayer was pretreated with different concentrations of PLC inhibitor U73122 $(2 \cdot 5,5,10 \mu \mathrm{mol} / \mathrm{l})$ or PKC inhibitor staurosporine $\left(10^{-9}, 10^{-8}, 10^{-7} \mathrm{~mol} / \mathrm{l}\right)$ for $30 \mathrm{~min}$. Thereafter, cells were incubated with $10^{-8} \mathrm{~mol} / 1$ melatonin for $1 \mathrm{~h}$ and processed for phagocytic assay. As controls, phagocytes were incubated: i) in medium alone for a total duration of $90 \mathrm{~min}$, ii) in medium alone for $30 \mathrm{~min}$ and then for $1 \mathrm{~h}$ with $10^{-8} \mathrm{~mol} / \mathrm{l}$ melatonin, and iii) initially for $30 \mathrm{~min}$ with highest concentration of U73122 $(10 \mu \mathrm{mol} / \mathrm{l})$ or staurosporine $\left(10^{-7} \mathrm{~mol} / \mathrm{l}\right)$, and then for $1 \mathrm{~h}$ in medium alone.

\section{Effect of adenylate cyclase inhibitor (SQ 22536) and PKA} inhibitor (H-89)

The phagocytes were preincubated with different concentrations of SQ $22536(1,10$, and $100 \mu \mathrm{mol} / \mathrm{l})$ for $30 \mathrm{~min}$ or $\mathrm{H}-89(0 \cdot 1,0 \cdot 5$, and $1 \mu \mathrm{mol} / \mathrm{l})$ for $20 \mathrm{~min}$ and then exposed to $10^{-8} \mathrm{~mol} / \mathrm{l}$ melatonin for $1 \mathrm{~h}$. To compare the results, phagocytes were incubated with $10^{-8} \mathrm{~mol} / 1$ melatonin 
alone. Cells incubated in either medium alone or with the highest concentration of SQ $22536(100 \mu \mathrm{mol} / \mathrm{l}) / \mathrm{H}-89$ $(1 \mu \mathrm{mol} / \mathrm{l})$ for the respective time periods were kept as separate control. After treatment, the phagocyte monolayer was washed and processed for phagocytosis.

\section{cAMP assay}

Intracellular cAMP was measured in melatonin-treated splenic phagocytes following the manufacturer's protocol (Sigma-Aldrich). In brief, $100 \mu \mathrm{l}$ cell suspension prepared in complete culture medium was transferred to each well of 96-well culture plate and incubated for $2 \mathrm{~h}$ to prepare the phagocyte monolayer. Instead of complete culture medium, PBS was used for the further incubations. The adhered phagocytes $\left(1 \times 10^{5}\right.$ cells $\left./ \mathrm{ml}\right)$ were incubated with phosphodiesterase inhibitor, IBMX $\left(10^{-4} \mathrm{~mol} / \mathrm{l}\right)$ for $30 \mathrm{~min}$ to inhibit the degradation of cAMP. Thereafter, the phagocytes were incubated with $10^{-8} \mathrm{~mol} / \mathrm{l}$ melatonin or in medium alone (control) for $1 \mathrm{~h}$. Subsequently, the supernatant was removed by centrifugation at $600 \mathrm{~g}$ and cells were lysed with $0 \cdot 1 \mathrm{~mol} / 1$ $\mathrm{HCl}$. Intracellular cAMP content was estimated with a commercially available enzyme immunoassay cAMP kit using a standard curve constructed with $0-200 \mathrm{pmol} / \mathrm{ml}$ cAMP.

\section{Cell viability}

The cell viability was assessed following MTT assay (Mossmann 1983) with minor modifications. It is based on the ability of mitochondrial dehydrogenase enzyme of viable cells to cleave the tetrazolium rings of MTT and form insoluble purple crystals of formazan. These crystals are impermeable to the cell membrane. The number of surviving cells is directly proportional to the level of the formazan product formed.

Splenic phagocytes were treated with varying concentrations of melatonin ranging from $10^{-12}$ to $10^{-8} \mathrm{~mol} / \mathrm{l}$. After $1 \mathrm{~h}$, cells were washed and incubated in $100 \mu \mathrm{l}$ of medium containing $0.5 \mathrm{mg} / \mathrm{ml}$ MTT for $2 \mathrm{~h}$ in 96 well culture plates. The phagocytes were washed with PBS and the reduced formazan crystals were solubilized in $150 \mu \mathrm{l}$ of DMSO. After incubation at room temperature for $15 \mathrm{~min}$, the absorbance was measured at $570 \mathrm{~nm}$. Cells incubated in medium alone for the respective time periods were considered controls.

\section{Statistical analysis}

Each experiment in triplicate was repeated thrice with phagocytes collected from different fish to verify the reproducibility of results. Data were statistically analyzed by Student's $t$-test $(P<0 \cdot 01)$ or one-way ANOVA (ANOVA; $P<0 \cdot 001)$ followed by Newman-Keuls' multiple range test. Data of one of the independent experiments are presented as mean \pm S.E.M.

\section{Results}

\section{Diurnal variation in phagocytic activity}

Splenic phagocytes isolated from fish maintained under $12 \mathrm{~h}$ light:12h darkness (photoperiod from 07:00 to 19:00 h) showed a marked diurnal variation in their phagocytic activity (Fig. 1). The phagocytosis was considerably higher during light phase than dark phase. When compared with 6:00 h, a marked increase $(P<0 \cdot 01)$ in phagocytic activity was observed at $12.00 \mathrm{~h}$. Furthermore, the level of phagocytic activity remained high till 18:00 h. However, a sharp decline in percentage phagocytosis and phagocytic index was observed at 24:00 $\mathrm{h}$ and it remained low throughout the dark phase till 6:00 h.

\section{Effect of $p C P A$ and melatonin replacement therapy}

The phagocytic activity of phagocytes collected from vehicleinjected fish was comparable with that of normal fish that were not subjected to any injection including vehicle. Hence, the data of vehicle-injected control was used for comparison with other treated groups.

The percentage phagocytosis and phagocytic index recorded during dark phase in short-term $\mathrm{pCPA}$-treated fish were remarkably $(P<0 \cdot 01)$ increased compared with that of vehicle-injected control (Fig. 2A). Similar results were achieved with long-term pCPA treatment (data not shown). The enhanced phagocytic activity of pCPA-treated fish was significantly decreased after administration of melatonin (Fig. 2A, pCPA versus pCPA + melatonin, $P<0 \cdot 01$ ).

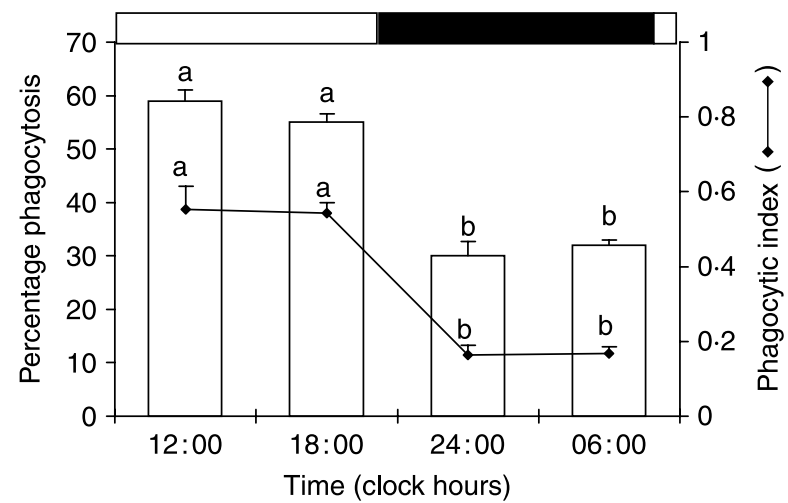

Figure 1 Diurnal variation in percentage phagocytosis (bar graph) and phagocytic index (line graph) of splenic phagocytes collected from $C$. punctatus maintained under $12 \mathrm{~h}$ light: $12 \mathrm{~h}$ darkness cycle (photoperiod from 07:00 to 19:00 h). After every $6 \mathrm{~h}$ intervals, spleen of four fish were pooled to prepare the monolayer in triplicate. The experiment was repeated thrice with different fish to verify the reproducibility of results. ${ }^{(a}$ and $\left.b\right)$ Error bars bearing different superscripts differ significantly (Newman-Keuls' multiple range test, $P<0 \cdot 01$ ). 

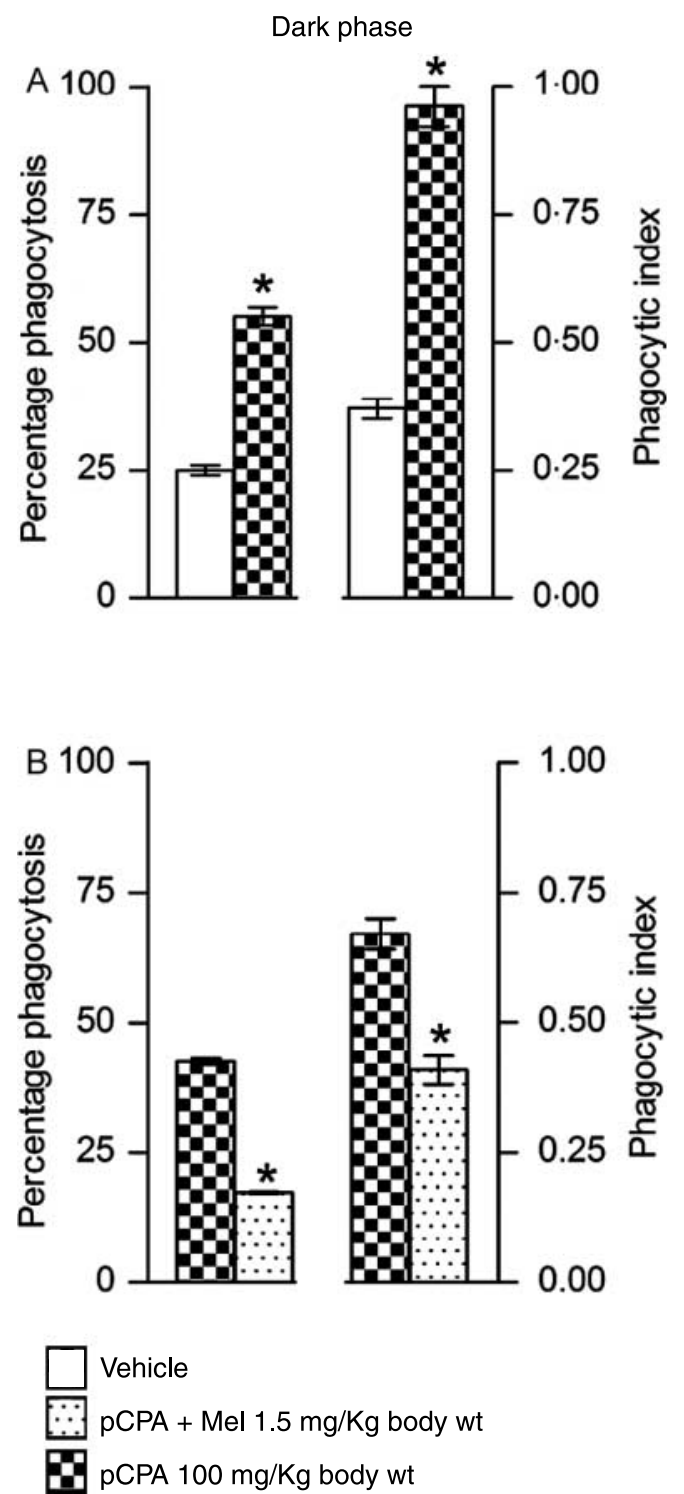

Figure 2 In vivo effect of (A) tryptophan hydroxylase inhibitor, parachlorophenylalanine (pCPA) and (B) pCPA + melatonin (melatonin replacement therapy) on percentage phagocytosis and phagocytic index of splenic phagocytes of $C$. punctatus. Fish were given single injection of pCPA or comparable volume of vehicle (control) at 18:00 h. For melatonin (Mel) replacement therapy, pCPA-treated fish were subjected to melatonin administration at 21:00 h. pCPA-treated fish subjected to vehicle injection were used as control. Fish of all the groups ( $n=4$ fish/group) were sacrificed at 24:00 h (dark phase). The monolayer for each group was prepared in triplicate to observe phagocytosis. Experiment was repeated thrice with phagocytes collected from different fish. Data of one of the independent experiments are presented as mean \pm S.E.M. (Student's $t$-test, ${ }^{*} P<0 \cdot 01$ ).

\section{Melatonin administration during light phase}

The low dose of melatonin $(0 \cdot 25 \mathrm{mg} / \mathrm{kg}$ body weight $)$ administered during light phase did not alter the phagocytosis. However, melatonin at $0.5 \mathrm{mg} / \mathrm{kg}$ body weight significantly
$(P<0 \cdot 01)$ decreased the phagocytic activity of splenic phagocytes when compared with vehicle-injected control or low dose melatonin-injected fish. The melatonin-induced decrease of phagocytosis increased considerably $(P<0 \cdot 01)$ with the increase of dose from 0.5 to $1.5 \mathrm{mg} / \mathrm{kg}$ body weight. However, no further reduction in phagocytic activity was observed when the dose of melatonin was increased to $3 \mathrm{mg} / \mathrm{kg}$ body weight as the effect was comparable with that observed at $1.5 \mathrm{mg} / \mathrm{kg}$ body weight (Fig. 3).

In vitro experiments

Time-dependent effect of melatonin Splenic phagocytes incubated with $10^{-8} \mathrm{~mol} / \mathrm{l}$ melatonin for different time intervals showed a time-dependent decrease in their phagocytic activity (Fig. 4A). Treatment of phagocytes with melatonin for $30 \mathrm{~min}$ significantly $(P<0 \cdot 01)$ inhibited the percentage phagocytosis and phagocytic index. The melatonin-induced suppression considerably $(P<0 \cdot 01)$ increased with the increase of incubation period to $60 \mathrm{~min}$. No further decrease in phagocytosis was observed when phagocytes were treated with melatonin for $90 \mathrm{~min}$ and the results were comparable with that recorded at $60 \mathrm{~min}$ incubation.

Concentration-dependent effect of melatonin Treatment of splenic phagocytes with different concentrations of melatonin ranging from $10^{-12}$ to $10^{-8} \mathrm{~mol} / \mathrm{l}$ showed the concentration-dependent decrease in phagocytosis (Fig. 4B). Melatonin at $10^{-12} \mathrm{~mol} / 1$ concentration was effective in inhibiting the percentage phagocytosis and phagocytic index when compared with control $(P<0 \cdot 01)$. The inhibition further increased with the increase in concentration.

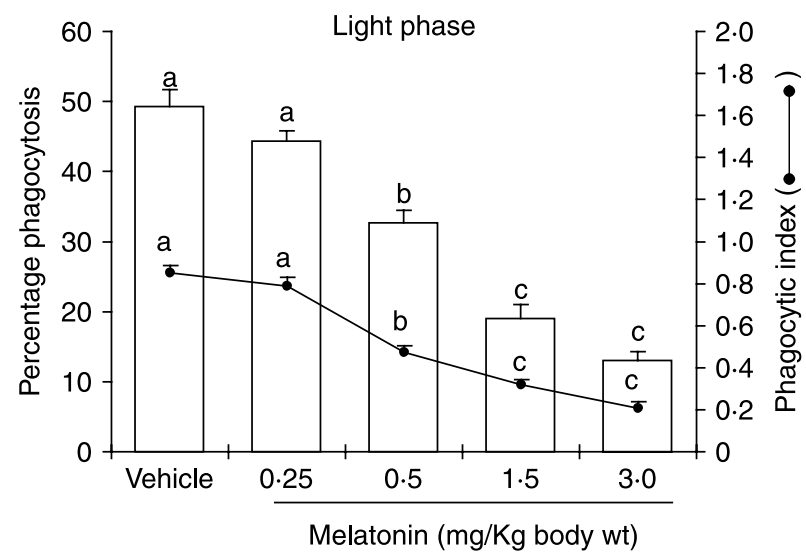

Figure 3 Effect of exogenous melatonin administration during light phase on phagocytosis in C. punctatus. Fish were administered varying doses of melatonin ( $n=4$ fish for each dose) at 09:00 $\mathrm{h}$ and sacrificed after $3 \mathrm{~h}$. Vehicle-injected fish were kept as control. The percentage phagocytosis is represented by bar graph and phagocytic index by the line graph. The experiment, in triplicate, was repeated thrice with different fish. Data of one of the independent experiments are presented as mean \pm s.E.M. Error bars bearing different superscripts differ significantly (Newman-Keuls' multiple range test, $P<0 \cdot 01$ ). 

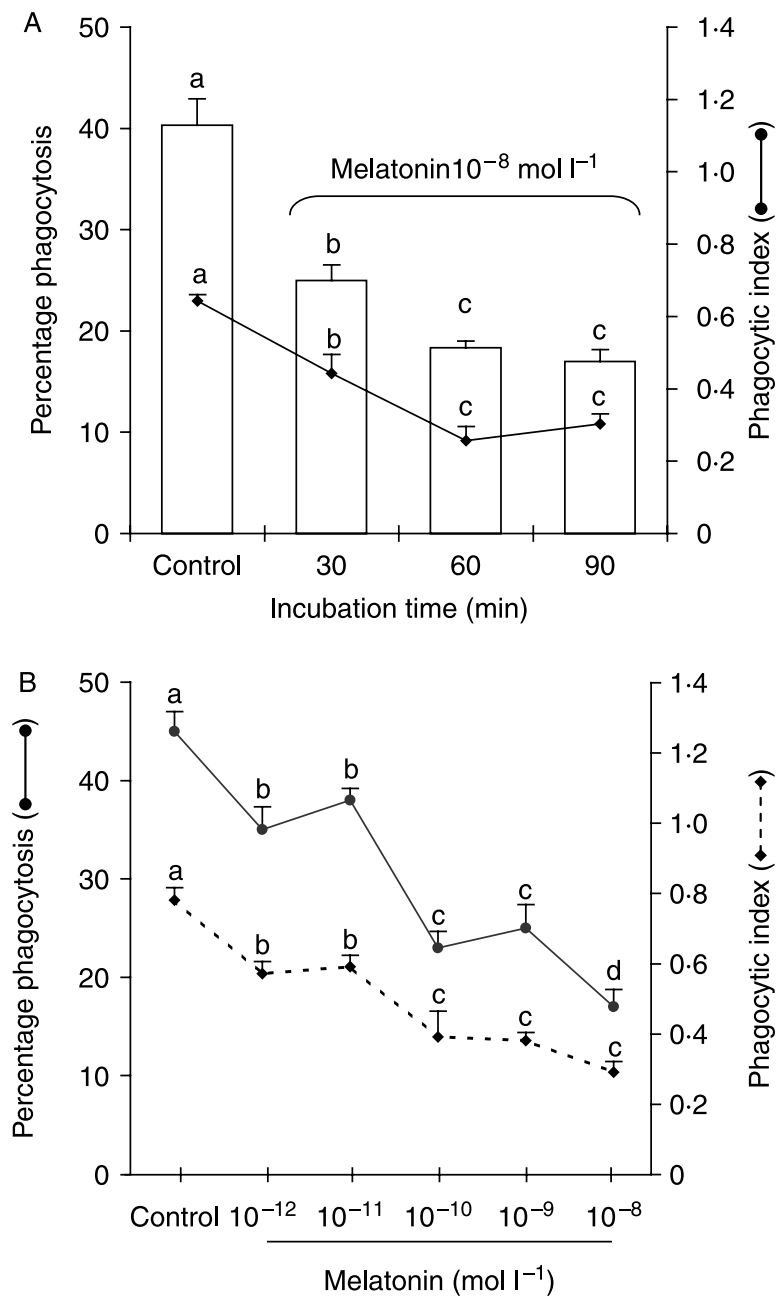

Figure 4 In vitro time- and concentration-dependent effect of melatonin on phagocytic activity of splenic phagocytes collected from $C$. punctatus. For time-dependent experiment (A), phagocytes were treated with $10^{-8} \mathrm{~mol} / \mathrm{I}$ melatonin for different time periods. As control, phagocytes were incubated in medium alone for a maximum duration of $90 \mathrm{~min}$. To study concentration efficacy (B), cells were incubated with varying concentrations of melatonin for $1 \mathrm{~h}$. The incubations were performed in triplicate, and repeated thrice with different fish (at each time, $n=4$ fish) to confirm the results. The data of one of the independent experiments are presented as mean \pm S.E.M. ${ }^{(a-c) /(a-d)}$ Error bars bearing different superscripts differ significantly (Newman-Keuls' multiple range test, $P<0 \cdot 01$ ).

The maximum suppression was recorded at $10^{-8} \mathrm{~mol} / \mathrm{l}$ concentration of melatonin $(P<0 \cdot 01)$. The cell viability was not influenced by melatonin at any concentration (Fig. 5).

Effect of melatonin receptor blocker (luzindole) Although luzindole alone at $10^{-6} \mathrm{~mol} / 1$ concentration did not have any effect on phagocytosis, preincubation of phagocytes with luzindole for $30 \mathrm{~min}$ completely blocked the melatonin $\left(10^{-8} \mathrm{~mol} / \mathrm{l}\right)$-induced suppression of percentage phagocytosis and phagocytic index (Fig. 6A and B).

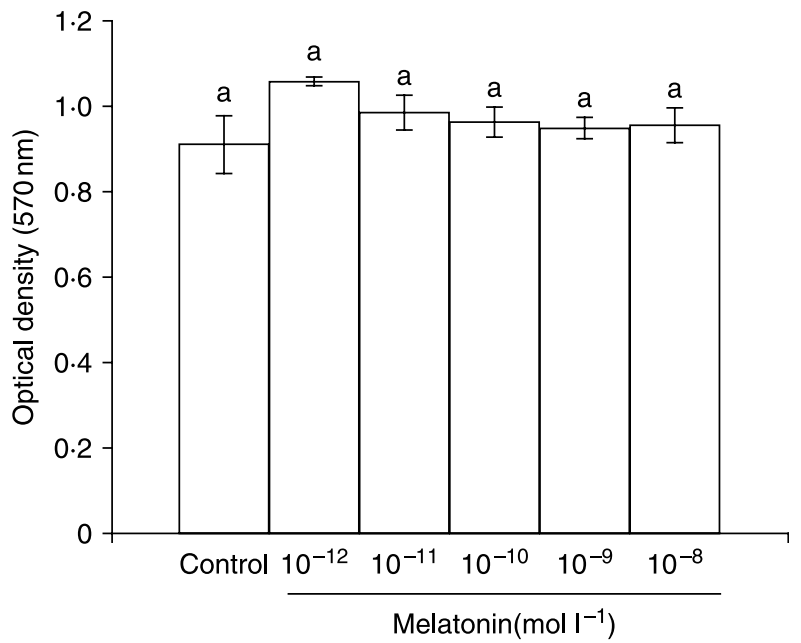

Figure 5 Effect of melatonin on viability of splenic phagocytes following MTT assay. Spleen of four fish were pooled to prepare the phagocyte monolayer. The monolayer in triplicate were incubated with varying concentrations of melatonin ranging from $10^{-12}$ to $10^{-8} \mathrm{~mol} / \mathrm{l}$. For control, phagocytes were incubated in medium alone for the respective time period $(1 \mathrm{~h})$. The experiment was repeated thrice with different fish. Data of one of the representative experiments are presented as mean \pm S.E.M. ${ }^{\text {a }}$ Error bars bearing same superscript do not differ significantly.

Effect of PLC inhibitor (U73122) and PKC inhibitor (staurosporine) PLC inhibitor U73122 did not alter the inhibitory effect of melatonin on phagocytosis by splenic phagocytes (Fig. 7). Similar results were noticed using PKC inhibitor, staurosporine (data not shown).

Effect of adenylate cyclase inhibitor (SQ 22536) and PKA inhibitor (H-89) SQ 22536 at $1 \mu \mathrm{mol} / 1$ significantly $(P<0 \cdot 01)$ decreased the suppressive effect of melatonin (Fig. 8). Moreover, it completely attenuated the melatonininduced suppression of phagocytic activity at higher concentrations (10 and $100 \mu \mathrm{mol} / \mathrm{l}$ ). Likewise, H-89 also downregulated the effect of melatonin on phagocytosis in a concentration-dependent manner $(P<0 \cdot 01$, Fig. 8$)$.

Intracellular cAMP The intracellular cAMP level in phagocytes incubated with PBS alone was 0.647 \pm $0 \cdot 107 \mathrm{pmol} / \mathrm{ml}$. Following incubation with melatonin for $1 \mathrm{~h}$, a fivefold increase in cAMP level was observed $(3 \cdot 36 \pm$ $0 \cdot 445 \mathrm{pmol} / \mathrm{ml} ; P<0 \cdot 01)$.

\section{Discussion}

The present study in freshwater fish C. punctatus, for the first time in ectothermic vertebrates, demonstrates the diurnal rhythmicity in phagocytic activity of splenic phagocytes. The phagocytosis was considerably higher during light phase than dark phase. This is in contrast to that in most of the endothermic vertebrates in which phagocytic activity remained elevated 

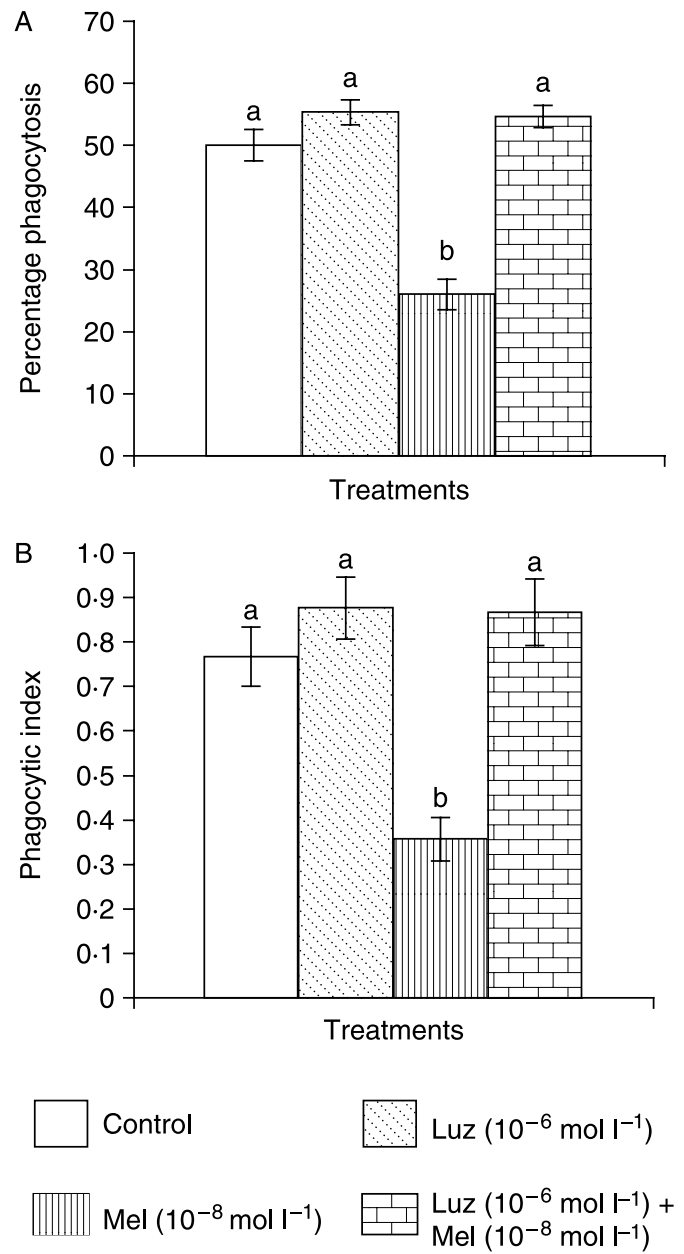

Figure 6 Effect of melatonin membrane receptor antagonist, luzindole (Luz), on melatonin (Mel)-induced inhibition of phagocytic activity of phagocytes from $C$. punctatus (A: percentage phagocytosis, B: phagocytic index). Splenic phagocytes were preincubated with Luz for $30 \mathrm{~min}$ and thereafter, treated with Mel for $1 \mathrm{~h}$. To compare the results, respective controls were as follows: (i) in medium alone (ii) with $10^{-6} \mathrm{~mol} / \mathrm{l} \mathrm{Luz} \mathrm{or} \mathrm{(iii)} 10^{-8} \mathrm{~mol} / \mathrm{l} \mathrm{Mel}$ alone. The experiment, in triplicate, was repeated thrice with phagocytes collected from different fish ( $n=4$ fish at each time). Data (mean \pm S.E.M.) represent the results of one of the independent experiments. ${ }^{(a}$ and b) Error bars bearing different superscripts differ significantly (Newman-Keuls' multiple range test, $P<0 \cdot 01$ ).

during the dark phase. However, the precise timing of acrophase varies in different animals. In ring doves (Rodríguez et al. 1999), rats (Hriscu et al. 2002-2003), and mice (Hriscu et al. 1998), the peak of phagocytosis is observed toward the end of the second half of dark span, whereas maximal phagocytic activity in guinea pig (Baciu et al. 1988) is demonstrated during first the half of the dark phase. Surprisingly, there are other studies in mice in which the acrophase of phagocytic activity is reported during the light phase. For example, the maximum engulfment of carbon particles by reticuloendothelial cells in CBA mice occur during the second half of the light span (Szabó et al. 1978), while

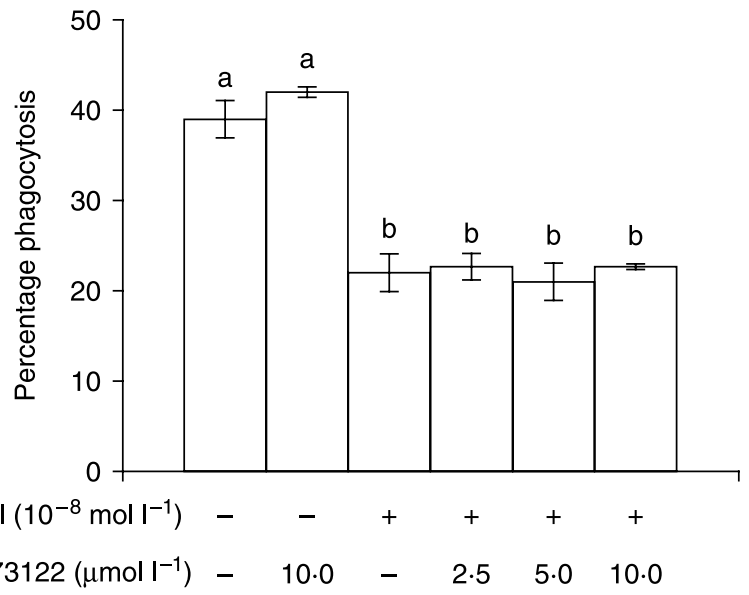

Figure 7 Effect of phospholipase C (PLC) inhibitor, U73122 on melatonin-induced decrease of phagocytosis. Splenic phagocytes collected from C. punctatus were pretreated with varying concentrations of U73122 for $30 \mathrm{~min}$, and then exposed to $10^{-8} \mathrm{~mol} / \mathrm{l}$ melatonin (Mel) for $1 \mathrm{~h}$. Respective control groups with $\mathrm{Mel} / \mathrm{U} 73122 /$ medium alone were made. The experiment was performed in triplicate ( $n=4$ fish), and repeated thrice with phagocytes collected from different fish. Data of one of the representative experiments are presented as mean \pm S.E.M. ${ }^{(a \text { and b) }}$ Error bars bearing same superscript do not differ. Similar results were obtained with PKC-inhibitor staurosporine (data not shown).

phagocytes collected from different tissues of C57BL/6 mice showed peak phagocytic activity in the first half of the light span (Knyszynski \& Fischer 1981, Hayashi et al. 2007). The inconsistent results pertaining to the circadian pattern of phagocytic activity are reported in humans also. The polymorphonuclear cells in one of the studies were unresponsive to the LD cycle (Bongrand et al. 1988), while the same cells exhibited diurnal periodicity with peak phagocytosis at midnight in the other study (Melchart et al. 1992). In ectothermic vertebrates, the knowledge is rudimentary and confined to a single report in which diurnal rhythmicity of humoral innate immune functions is described in fishes, gilthead seabream, and sea bass (Esteban et al. 2006). The peak complement activity in both fishes is reported during the light phase which is in parallel to our results for phagocytic activity of splenic phagocytes in $C$. punctatus. However, different acrophase has been shown for lysozyme and peroxidase activities in seabream. The maximum lysozyme activity was recorded during the first half of the dark phase (20:00 and 2:00 h), while high peroxidase activity was restricted to early light phase $(8: 00 \mathrm{~h})$. Intriguingly, in sea bass, the light:darkness cycle had hardly any effect on lysozyme or peroxidase activity. Taken together, the pattern of circadian rhythmicity of immune responses seems to be dependent on species, strain of animals, and type of immune cells and their specific functions.

In endothermic vertebrates, irrespective of whether they are diurnal or nocturnal, a positive correlation between levels of plasma melatonin and phagocytic activity of leukocytes has been reported (Rodriguez et al. 1999, Barriga et al. 2001). 


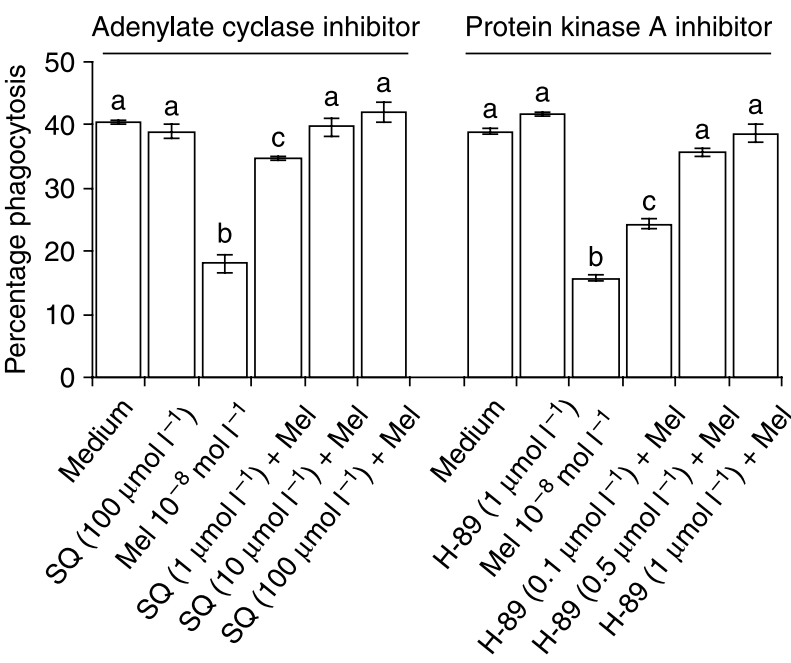

Figure 8 Concentration-depenedent effect of adenylate cyclase inhibitor SQ 22536 (SQ) and protein kinase A (PKA) inhibitor (H-89) on the inhibitory effect of melatonin on phagocytic activity. Splenic phagocytes from $C$. punctatus were preincubated with SQ for $30 \mathrm{~min} / \mathrm{H}-89$ for $20 \mathrm{~min}$ and then treated with $10^{-8} \mathrm{~mol} / \mathrm{I}$ melatonin. The respective controls were run in parallel. The experiment was repeated thrice with different fish (at each time, $n=4$ fish). Data (mean \pm s.E.M.) represent the results of one of the independent experiments. ${ }^{(\mathrm{a}-\mathrm{c})}$ Error bars bearing different superscripts differ significantly (Newman-Keuls' multiple range test, $P<0 \cdot 01$ ).

However, experimental evidence implicating the role of melatonin in regulation of diurnal variation in phagocytosis is lacking. In the present study, administration of pCPA, an irreversible tryptophan hydroxylase inhibitor known to diminish melatonin biosynthesis (Carrillo-Vico et al. 2005), completely abolished the decrease in phagocytosis observed during dark phase. The decreased melatonin level might be implicated for this effect though the serum melatonin was not measured in these spotted murrel fish. Our speculation was strengthened by the experiment in which melatonin replacement therapy reversed the $\mathrm{pCPA}$ effect. Also, in a separate experiment, melatonin administration during the light phase in normal fish decreased the phagocytosis. These in vivo results in C. punctatus were further corroborated by in vitro experiments.

The in vitro experiment in the present study exhibited the concentration-dependent inhibitory effect of melatonin on phagocytic activity of splenic phagocytes. This is in contradiction to the reports in endothermic vertebrates in which melatonin is shown to have immunoenhancive effects (Guerrero \& Reiter 2002). In particular, melatonin increased the phagocytic activity of heterophils in ring doves and the effect was more pronounced at the concentration present during night-time (Terron et al. 2002). A similar effect on phagocytosis is seen in rat though the macrophages were isolated from testis (Pawlak et al. 2005). As far as the direct evidence on the role of melatonin in control of phagocyte innate immune responses in ectothermic vertebrates is concerned, the report is confined to a single in vitro study in fishes in which melatonin had diverse effects, depending on fish species and immune parameter studied (Cuesta et al. 2007). In contrast to our results, melatonin failed to affect the phagocytic activity of head-kidney leucocytes in fishes, sea bass, and seabream. On the other hand, melatonin decreased the peroxidase activity in these fishes. With regard to respiratory burst activity, the effect of melatonin is fish specific, stimulatory in sea bass while ineffective in seabream. Nevertheless, the results of the present study in conjunction with reports in other vertebrates, including fish, suggest the direct role of melatonin in modulation of phagocyte innate immune responses.

Regarding the mode of melatonin action, membrane bound receptors for melatonin on immune cells is demonstrated in avian and mammalian species (Guerrero \& Reiter 2002). In fish, cDNAs encoding different melatonin receptor subtypes have been cloned and their functional properties assayed in several tissues such as brain, pineal gland, pituitary gland, retina, gill, liver, and skin. The partial sequence for all three receptor subtypes, $\mathrm{Mel}_{1 \mathrm{a}}, \mathrm{Mel}_{1 \mathrm{~b}}$, and $\mathrm{Mel}_{1 \mathrm{c}}$, are cloned from zebrafish (Reppert et al. 1995), while in rainbow trout (Mazurais et al. 1999) and pike (Gaildrat \& Falcón 2000) only $\mathrm{Mel}_{1 \mathrm{a}}$ and $\mathrm{Mel}_{1 \mathrm{~b}}$ are cloned so far. In addition, full length sequence is available for trout MT1 (AF156262), pike $\mathrm{Mel}_{1 \mathrm{~b}}$ (Gaildrat et al. 2002) and rabbitfish MT1 and $\mathrm{Mel}_{1 \mathrm{c}}$ (Park et al. $2007 a, b)$. Recently, full length cloning and expression of three different melatonin receptor subtypes, MT1, MT2, and $\mathrm{Mel}_{1 \mathrm{c}}$ have been reported in European sea bass, Dicentrarchus labrax (Sauzet et al. 2008). This study has demonstrated the presence of melatonin receptor, in particular MT2, for the first time on blood cells in a fish model, and indicated the possibility of melatonins involvement in the regulation of blood cell immune responses. In the present study, the existence of functional membrane-bound melatonin receptors on phagocytes was shown using melatonin receptor blocker, luzindole. The effect of melatonin on phagocytic activity of splenic phagocytes in C. punctatus was completely blocked by luzindole. The membrane-bound receptors mediating melatonin effect on testicular macrophage phagocytosis is also pharmacologically demonstrated in rat (Pawlak et al. 2005).

In the present study, adenylate cyclase inhibitor and PKA inhibitor attenuated the inhibitory effect of melatonin on phagocytosis, suggesting that melatonin following cAMPPKA pathway decreased the phagocytic response of splenic phagocytes in C. punctatus. Further, the increase in intracellular cAMP level in response to melatonin and the results of our earlier in vitro study in C. punctatus in which cAMP analog decreased phagocytosis (Roy \& Rai 2008) corroborates the assumption. By contrast, melatonin is reported to decrease the intracellular cAMP levels in murine peritoneal macrophages (García-Pergañeda et al. 1999) and human lymphocytes (García-Pergañeda et al. 1997). Also, a decrease in intracellular cAMP is shown to enhance phagocytosis in murine peritoneal macrophages (Lima et al. 1974). An inverse relationship between cAMP and phagocytic activity of splenic macrophages has been demonstrated also in 
wall lizards (Roy \& Rai 2004). In the case of chicks, intriguingly, opposite effects of melatonin are observed on cAMP and IP3 production in the same cell depending on the activation state of cells and the involvement of specific subtypes of melatonin receptors. Melatonin via $\mathrm{Mel}_{1 \mathrm{c}}$ receptors decreases intracellular cAMP and increases IP3 in unstimulated chick splenocytes (Markowska et al. 2004), whereas in PHA-stimulated splenocytes it increases cAMP levels and decreases IP3 acting through MT2 receptors (Markowska et al. 2002). Based on diacylglycerol production, increased PLC activity is also implicated for melatonin signaling mechanism in human lymphocyte (García-Pergañeda et al. 1997). In C. punctatus, however, cAMP seems to be exclusively involved in mediating melatonin effect on phagocytic activity of splenic phagocytes as the inhibitors of PLC and PKC failed to alter the effect of melatonin on phagocytosis.

To conclude, the present study in freshwater fish $C$. punctatus describes the diurnal rhythmicity of phagocytic activity of splenic phagocytes. The phagocytosis is higher during light phase when compared with dark phase. Melatonin might be implicated in causing the decreased phagocytosis during dark phase acting through membranebound melatonin receptors coupled to adenylate cyclasecAMP-PKA pathway.

\section{Declaration of interest}

The authors declare that there is no conflict of interest that would prejudice the impartiality of this scientific work.

\section{Funding}

The authors are thankful to Indian Council of Agricultural Research (ICAR), PUSA, New Delhi, India for financial support.

\section{Acknowledgements}

The first author of the paper is indebted to Council of Scientific and Industrial Research, India for scholarship provided.

\section{References}

Baciu I, Olteanu A, Prodan T, Baiescu M \& Vaida A 1988 Changes of phagocytic biological rhythm by reduction of circadian times and by influences upon hypothalamus. International Journal of Neuroscience 41 143-153.

Barriga C, Martin MI, Tabla R, Ortega E \& Rodríguez AB 2001 Circadian rhythm of melatonin, corticosterone and phagocytosis: effect of stress. Journal of Pineal Research 30 180-187.

Berger J \& Slapničková M 2003 Circadian structure of rat neutrophil phagocytosis. Comparative Clinical Pathology 12 84-89.

Bongrand P, Bouvenot G, Bartolin R, Tatossian J \& Bruguerolle B 1988 Are there circadian variations of polymorphonuclear phagocytosis in man? Chronobiology International 5 81-83.
Carrillo-Vico A, Calvo JR, Abreu P, Lardone PJ, García-Mauriño S, Reiter RJ \& Guerrero JM 2004 Evidence of melatonin synthesis by human lymphocytes and its physiological significance: possible role as intracrine, autocrine, and/or paracrine substance. FASEB Journal 18 537-539.

Carrillo-Vico A, Lardone PJ, Fernández-Santos JM, Martín-Lacave I, Calvo JR, Karasek M \& Guerrero JM 2005 Human lymphocyte-synthesized melatonin is involved in the regulation of the interleukin-2/interleukin-2 receptor system. Journal of Clinical Endocrinology and Metabolism $\mathbf{9 0}$ 992-1000.

Conti A, Conconi S, Hertens E, Skwarlo-Sonta K, Markowska M \& Maestroni JM 2000 Evidence for melatonin synthesis in mouse and human bone marrow cells. Journal of Pineal Research 28 193-202.

Cuesta A, Rodríguez A, Calderón MV, Meseguer J \& Esteban MA 2007 Effect of the pineal hormone melatonin on teleost fish phagocyte innate immune responses after in vitro treatment. Journal of Experimental Zoology 307 509-515.

Esteban MA, Cuesta A, Rodríguez A \& Meseguer J 2006 Effect of photoperiod on the fish innate immune system: a link between fish pineal gland and the immune system. Journal of Pineal Research 41 261-266.

Falcón J, Besseau L, Fazzari D, Attia J, Gaildrat P, Beauchaud M \& Boeuf G 2003 Melatonin modulates secretion of growth hormone and prolactin by trout pituitary glands and cells in culture. Endocrinology 144 4648-4658.

Falcón J, Besseau L, Sauzet S \& Boeuf G 2007 Melatonin effects on the hypothalmo-pituitary axis in fish. Trends in Endocrinology and Metabolism 18 81-88.

Finocchiaro LME, Artz ES, Fernández-Castelo S, Criscuolo ME, Finkielman S \& Nahmod VE 1988 Serotonin and melatonin synthesis in peripheral blood mononuclear cells: stimulation by interferon $-\gamma$ as part of an immunomodulatory pathway. Journal of Interferon Research 1988 705-716.

Finocchiaro LME, Nahmod VE \& Launay JM 1991 Melatonin biosynthesis and metabolism in peripheral blood mononuclear leucocytes. Biochemical Journal $280727-731$.

Gaildrat P \& Falcón J 2000 Melatonin receptors in the pituitary of a teleost fish: mRNA expression, 2-[125I] iodomelatonin binding and cyclic AMP response. Neuroendocrinology 72 57-66.

Gaildrat P, Becq F \& Falcón J 2002 First cloning and functional characterization of a melatonin receptor in fish brain: a novel one? Journal of Pineal Research 32 74-84.

García-Pergañeda A, Pozo D, Guerrero JM \& Calvo JR 1997 Signal transduction for melatonin in human lymphocytes: involvement of a pertussis toxin-sensitive G protein. Journal of Immunology 159 3774-3781.

García-Pergañeda A, Guerrero JM, Rafii-El-Idrissi M, Paz Romero M, Pozo D \& Calvo JR 1999 Characterization of membrane melatonin receptor in mouse peritoneal macrophages: inhibition of adenylyl cyclase by a pertussis toxin-sensitive G protein. Journal of Neuroimmunology 95 85-94.

Guerrero JM \& Reiter RJ 2002 Melatonin-immune system relationships. Current Topics in Medicinal Chemistry 2 167-179.

Hayashi M, Shimba S \& Tezuka M 2007 Characterization of the molecular clock in mouse peritoneal macrophages. Biological \& Pharmaceutical Bulletin $30621-626$.

Hriscu M 2004 Circadian phagocytic activity of neutrophils and its modulation by light. Journal of Applied Biomedicine 2 199-211.

Hriscu M, Saulea G, Vidrascu N \& Baciu I 1998 Circadian rhythm of phagocytosis in mice. Romanian Journal of Physiology 35 319-323.

Hriscu M, Saulea G, Ostriceanu S \& Baciu I 2002-2003 Circadian phagocytic activity in rats under light-dark and constant light regimens. Romanian Journal of Physiology 39-40 17-26.

Joy KP \& Khan IA 1991 Pineal-gonadal relationship in the teleost Channa punctatus (Bloch): evidence for possible involvement of hypothalamic serotonergic system. Journal of Pineal Research 11 12-22.

Kezuka H, Furukawa K, Aida K \& Hanyu I 1988 Daily cycles in plasma melatonin levels under long or short photoperiod in the common carp, Cyprinus carpio. General and Comparative Endocrinology 72 296-302.

Knyszynski A \& Fischer H 1981 Circadian fluctuations in the activity of phagocytic cells in blood, spleen, and peritoneal cavity of mice as measured by zymosan-induced chemiluminescence. Journal of Immunology 127 $2508-2511$ 
Lima AO, Javierre MQ, Da Silva WD \& Camara DS 1974 Immunological phagocytosis: effects of drugs on phophodiestrase activity. Experientia $\mathbf{3 0}$ 945-946.

Manning MJ \& Nakanishi T 1996 The specific immune system: cellular defenses. In The Fish Immune System: Organism, Pathogen, and Environment, pp 159-205. Eds G Iwama \& T Nakanishi. New York: Academic Press.

Markowska M, Mrozkowiak A \& Skwarlo-Sońta K 2002 Influence of melatonin on chicken lymphocytes in vitro: involvement of membrane receptors. Neuroendocrinology Letters 23 67-72.

Markowska M, Mrozkowiak A, Pawlak J \& Skwarlo-Sońta K 2004 Intracellular second messengers involved in melatonin signal transduction in chicken splenocytes in vitro. Journal of Pineal Research 37 207-212.

Mazurais D, Brierley I, Anglade I, Drew J, Randall C, Bromage N, Michel D, Kah O \& Williams LM 1999 Central melatonin receptors in the rainbow trout: comparative distribution of ligand binding and gene expression. Journal of Comparative Neurology 409 313-324.

Melchart D, Martin P, Hallek M, Holzmann M, Jurcic X \& Wagner H 1992 Circadian variation of the phagocytic activity of polymorphonuclear leukocytes and of various other parameters in 13 healthy male adults. Chronobiology International 9 35-45.

Mosmann T 1983 Rapid colorimetric assay for cellular growth and survival: application to proliferation and cytotoxicity assays. Journal of Immunological Methods 65 55-63.

Neumann NF, Stafford JL, Barreda D, Ainsworth AJ \& Belosevic M 2001 Antimicrobial mechanisms of fish phagocytes and their role in host defense. Developmental and Comparative Immunology 25 807-825.

Park YJ, Park JG, Hiyakawa N, Lee YD, Kim SJ \& Takemura A 2007a Diurnal and circadian regulation of a melatonin receptor, MT1, in the golden rabbitfish, Siganus guttatus. General and Comparative Endocrinology 150 253-262.

Park YJ, Park JG, Jeong HB, Takeuchi Y, Kim SJ, Lee YD \& Takemura A $2007 b$ Expression of the melatonin receptor Mel (1 c) in neural tissues of the reef fish Siganus guttatus. Comparative Biochemistry and Physiology, Part A 147 103-111.

Pawlak J, Singh J, Lea RW \& Skwarlo-Sonta K 2005 Effect of melatonin on phagocytic activity and intracellular free calcium concentration in testicular macrophages from normal and streptozotocin-induced diabetic rats. Molecular and Cellular Biochemistry 275 207-213.
Randall CF, Bromage NR, Thorpe JE, Miles MS \& Muir JS 1995 Melatonin rhythms in Atlantic salmon (Salmo salar) maintained under natural and outof-phase photoperiods. General and Comparative Endocrinology 98 73-86.

Reppert SM, Weaver DR, Cassone VM, Godson C \& Kolakowski LF 1995 Melatonin receptors are for the birds: molecular analysis of two receptor subtypes differentially expressed in chick brain. Neuron 15 1003-1015.

Rodríguez AB, Marchena JM, Nogales G, Durán J \& Barriga C 1999 Correlation between the circadian rhythm of melatonin, phagocytosis, and superoxide anion levels in ring dove heterophils. Journal of Pineal Research 26 35-42.

Roy B \& Rai U 2004 Dual mode of catecholamine action on splenic macrophage phagocytosis in wall lizard, Hemidactylus flaviviridis. General and Comparative Endocrinology 136 180-191.

Roy B \& Rai U 2008 Role of adrenoceptor-coupled second messenger system in sympatho-adrenomedullary modulation of splenic macrophage functions in live fish Channa punctatus. General and Comparative Endocrinology 155 298-306.

Sauzet S, Besseau L, Herrera PP, Covès D, Chatain B, Peyric E, Boeuf G, Muñoz-Cueto JA \& Falcón J 2008 Cloning and retinal expression of melatonin receptors in the European sea bass, Dicentrarchus labrax. General and Comparative Endocrinology 157 186-195.

Szabó I, Kovats TG \& Halberg F 1978 Circadian rhythm in murine reticuloendothelial function. Chronobiologia 5 137-143.

Terron MP, Cubero J, Marchena JM, Barriga C \& Rodriguez AB 2002 Melatonin and aging: in vitro effect of young and mature ring dove physiological concentrations of melatonin on the phagocytic function of heterophils from old ring dove. Experimental Gerontology 37 421-426.

Zachmann A, Knijff SCM, Ali MA \& Anctil M 1992 Effects of photoperiod and different intensities of light exposure on melatonin levels in the blood, pineal organ, and retina of the brook trout (Salvelinus fontinalis Mitchill). Canadian Journal of Zoology 70 25-29.

Received in final form 22 September 2008

Accepted 25 September 2008

Made available online as an Accepted Preprint 29 September 2008 